\section{Does Effective Diastolic Coronary Venous Retroperfusion Depend on Arterial-Like Blood Pressure in the Coronary Sinus?}

\author{
PIETER D. VERDOUW, PhD \\ KEVIN BEATT, MD \\ LUUK BERK, MD \\ PATRICK W. SERRUYS, MD, PhD
}

In $\mathrm{n}$ a number of studies, synchronized diastolic retroperfusion instituted 20 minutes after coronary artery occlusion has been shown to enhance recovery of regional contractile function..$^{1-3}$ We hypothesized that, if retroperfusion was started before the onset of ischemia, it might prevent or at least delay the loss of regional function.

We therefore conducted a series of experiments in which we looked at the effects of retroperfusion on Yorkshire pigs (18 to $45 \mathrm{~kg}$ ), anesthetized and instrumented as described previously. ${ }^{4}$ The retroperfusion system (model EC-1, USCI division of C.R. Bard] was set to pump 35 to $40 \mathrm{ml} \cdot \mathrm{min}^{-1}$ of arterial blood retrogradely into the coronary sinus starting just before $a$ 20-minute occlusion of the left anterior descending coronary artery. Within 2 minutes of occlusion, we observed in the control and retroperfusion groups similar decreases in cardiac output $(-0.3 \pm 0.2$ and 0.3 \pm 0.1 liter $\cdot \mathrm{min}^{-1}$, respectively], mean arterial blood pressure $[-12 \pm 3$ and $-12 \pm 3 \mathrm{~mm} \mathrm{Hg}$ and maximum rate of rise in left ventricular pressure $(-370 \pm 90$ and $-450 \pm 60 \mathrm{~mm} \mathrm{Hg} \cdot \mathrm{s}^{-1}$ ), and an increase in left ventricular end-diastolic blood pressure $[4 \pm 1$ and $3 \pm 1$ $\mathrm{mm} \mathrm{Hg}$ ). These changes persisted during the remainder of the occlusion period. During reperfusion, the recovery of the hemodynamic parameters in both groups was similar in time and magnitude. In the untreated animals coronary artery occlusion resulted in a loss of systolic wall thickening (from $30 \pm 3$ to $6 \pm 3 \%$ ) within 2 minutes. No recovery was seen during the 2 first hours of reperfusion. Retroperfusion neither modified the loss of regional function during occlusion (from $32 \pm 3$ to $5 \pm 3 \%$ ) nor enhanced its recovery during reperfusion.

In pigs, the residual flow after coronary artery ligation is $<5 \%$ of the preocclusion value and a reduction of flow to approximately $30 \%$ of baseline will result in a complete loss of function. This implies that retroperfusion must increase the flow to the ischemic area by at least this amount before any improvement in function can be expected. In the canine model it has been shown that $50 \%$ of the delivered retroperfusion flow is

From the Laboratory for Experimental Cardiology, Thoraxcenter, Erasmus University Rotterdam, Rotterdam, the Netherlands. Dr. Beatt is the recipient of a research fellowship from the British and Netherlands Heart Foundations. Manuscript received August 10, 1987; revised manuscript received February 8 , 1988, and accepted February 14. able to reach the ischemic myocardium. If this applies to the pig, an improvement in function should have been observed. It is unclear why no improvement in function was seen, as theoretically a sufficient volume of blood [ 30 to $40 \mathrm{ml} \cdot \mathrm{min}^{-1}$ ] was delivered by the retroperfusion system into the coronary sinus of these pigs, which normally have left anterior descending coronary artery flow values of 30 to $40 \mathrm{ml} \cdot \mathrm{min}^{-1}$.

Recovery of regional myocardial function in pigs during the first 2 hours after a 20 -minute coronary artery occlusion is minimal. ${ }^{5}$ In the same model enhanced recovery is possible by pretreating the animals with the stable prostacyclin analog Iloprost. ${ }^{5}$ After the initial series we performed 3 additional experiments in which the retroperfusion flow rate was increased until some effect on regional contractile function was observed. Some regional wall thickening returned with rates of $60 \mathrm{ml} \cdot \mathrm{min}^{-1}$ but this was with selective catheter positioning high in the anterior cardiac vein. Higher flow rates and coronary sinus pressures were necessary to achieve sustained improvement (Figure 1). Temporary cessation of retroperfusion resulted in loss of wall thickening (which returned once retroper-
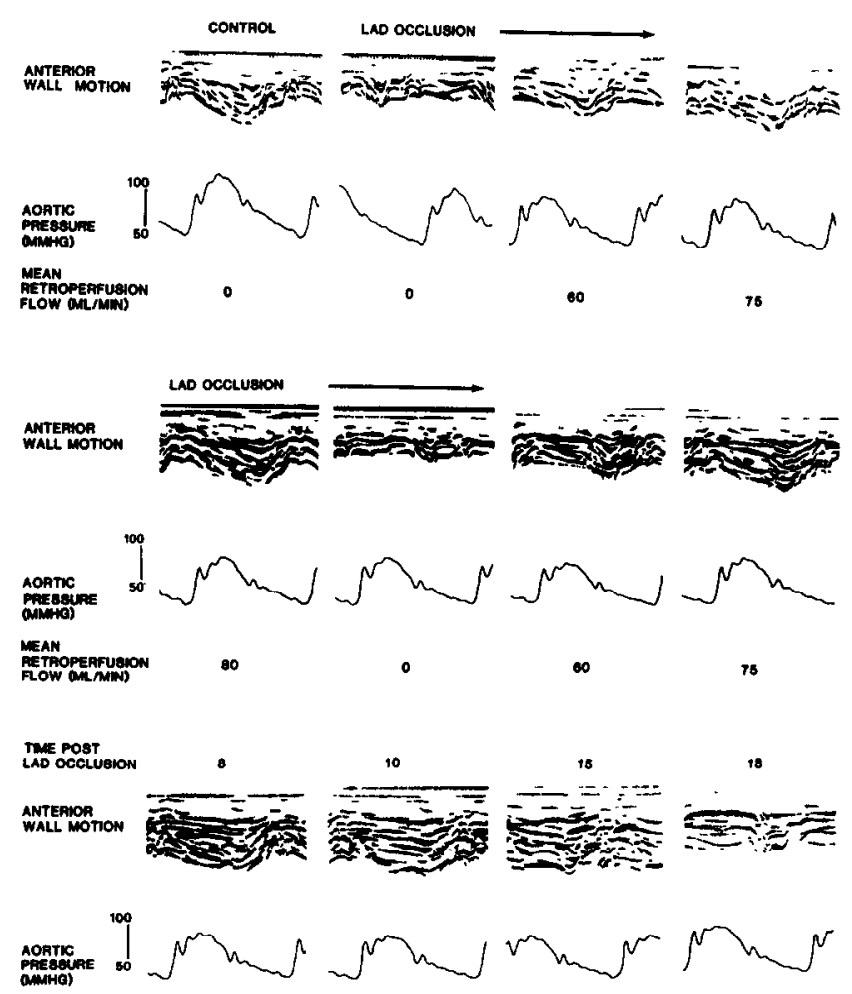

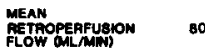

FIGURE 1. The changes in left ventrlcular anterior wall motion and aortic pressure during left anterior descending (LAD) coronary artery occlusion are compared with baseline recordings. The retroperfusion flow rates are shown under these recordings. The top row shows the loss of anterlor wall motion with LAD occluslon and the subsequent improvement with flow rates of 60 and $75 \mathrm{ml} \cdot \mathrm{min}^{-1}$; the second row shows the loss of motion with the retroperfusion cessation, which returns when flow is restarted. The bottom row shows the progressive thlckening and loss of function with continued retroperfusion at $80 \mathrm{ml} \cdot \mathrm{min}^{-1}$. 
fusion was restarted). Continuous pumping at these higher flow rates caused a progressive increase in coronary sinus pressure that varied from 80 to $120 \mathrm{~mm} \mathrm{Hg}$ and led to a loss of systolic wall thickening of the jeopardized myocardium.

We believe that at these higher flow rates the systolic time interval available for venous drainage is not sufficient to cope with the increased volume of blood delivered. The limited amount of data available suggests that effective retroperfusion depends on the retroperfusion pressure, which in turn is dependent on the capacitance and compliance of the individual coronary venous system. It is at present unknown whether there is a retroperfusion pressure that may be safely used for prolonged periods without risk of developing myocardial edema. In the absence of this data, extreme care must be exercised when using this system in the clinical setting, especially because the experimental data do not always support such use. ${ }^{6}$

1. Yamazaki S, Drury JK, Meerbaum S. Corday E. Synchronuzed coronary venous retroperfusion: prompt improvement of left ventricular function in experimental myocardial ischemia. JACC 1985;5.655-663.

2. Drury IK Yamazaki S, Fishbein MC. Meerbaum S, Corday E. Synchronized diastolic coronary venous retroperfusion: results of a preclinical safety and efficacy study. IACC 1985;6:328-335.

3. Berdeaux A. Farcot IC. Bourdarias JP, Barry M, Bardet J, Giudicelli JF. Effects of diastolic synchronized retroperfusion on regional coronary blood flow in experimental myocardial ischemia. Am I Cardiol 1981;47:10331040.

4. Verdouw PD, Hartog JM, Saxena PR, Hugenholtz PG. Systemic and regıonal hemodynamic, antiarrhythmic and antiischemic effects of bevantolol in anesthetized pigs. Am / Cardiol 1986;58:8E-16E.

5. Van der Giessen WJ, Mooi WJ, Rutteman AM, Berk L, Verdouw PD. The effect of the stable prostacyclin analogue ZK 36374 on experimental coronary thrombosis in the pig. Thromb Res 1984;36:45-51.

6. Beatt KJ, Serruys PW, de Feyter P, van den Brand M, Verdouw PD, Hugenholtz PG. Hemodynamic observations during PTCA in the presence of synchronized diastolic coronary sinus retroperfusion. Br Heart J 1988;59:159-167.

\section{The AJC in May 1963}

\author{
WILIAM C. ROBERTS, MD
}

he AJC in May 1963 contained 18 articles, occupying 130 pages, including 1 editorial, 9 major reports, 7 case reports and 1 address. This piece will comment on 3 articles.

In the lead editorial entitled "Some paradoxes in the history of pulsus paradoxus" William Dock ${ }^{1}$ from Brooklyn, New York, wrote:

I propose to call this pulse the paradox, partly because of the striking disparity between heart action and arterial pulse, partly because the pulse, in spite of apparent irregularity, really is one which becomes intermittent or small in regular recurrence. In the neck veins, with sufficiently deep inspiration, the constricting pull of the fibrous bands causes a visible, even a considerable bulging instead of the normal shrinking. Kussmaul's use of the noun 'paradox' to characterize the invariable arterial and venous phenomena seen in heart failure due to constrictive pericarditis set off a chain reaction of paradoxes.

All the phenomena described by Kussmaul may occur in severe heart failure, especially that which comes on rapidly and affects the right ventricle as well as the left, in the absence of all types of pericardial adhesions, pericardial tamponade or subendocardial fibrosis. Yet many clinicians continue to regard these phenomena as 'diagnostic' of a pericardial cause of congestive failure. A most disturbing paradox!

... it might be well to dwell on the truly paradoxic rise in venous pressure during inspiration and to remember that the drop in strength of the pulse is brief and often only barely demonstrable. In cases of air hunger without heart failure, the pulse decrease may be profound and prolonged, but since no one suspects pericardial disease, no one notices it. In air hunger, the neck veins collapse and stay empty during inspiration; in heart disease they may fail to collapse and may expand further in paradoxic fashion. Finally, all the phenomena of true pulsus paradoxus occur without pericardial disease, when heart failure is so rapid and severe that the dilated chambers fill the pericardial sac and draw its fibers to a high tension even during expiration. The lack of emphasis on the fact that pulsus paradoxus is not diagnostic of pericardial disease is the most curious of the paradoxes ...

The lead article was by Wigle and associates ${ }^{2}$ from Toronto, Canada, and they described results of septotomy without septectomy for obstructive hypertrophic cardiomyopathy in 4 patients. The obstruction to left ventricular outflow was abolished in all 4 patients and marked symptomatic and hemodynamic improvement occurred in 3.

This issue also included publication of the Convocation Address by Paul Dudley White ${ }^{3}$ from Boston, Massachusetts, to the Twelfth Annual Meeting of the American College of Cardiology. Entitled "Refections of a pioneer in cardiology," White's message discussed 4 "precepts": (1) the patient himself; (2) a book of rules; (3) advice to cardiologists, and (4) the field of cardiology. Under item 2 he emphasized that physicians must

... begin now to apply simple and sensible, positive rules of health, even before we can establish them statistically as 100 percent valid. Wherever in the world people eat richly of calories and animal fat ... there we find much atherosclerosis ... There is increasing evidence that vigorous muscular contraction has a antiatherogenic effect ... Muscular fatigue is probably the best tranquilizer and antidote for stress ... Leg muscles when in good tone and contracting, pump blood upward against gravity ... Hence, I now recommend ... muscular exercise, to all the world for its three effects, physiologic, psychologic and probably also antiatherogenic.

1. Dock W. Some paradoxes in the history of pulsus paradoxus. Am J Cardiol 1963;11:569-571.

2. Wigle ED, Chrysohou A, Bigelow WG. Results of ventriculomytomy in muscular subaortic stenosis. Am I Curdiol 1963;11:572-586

3. White PD. Reflections of a pioneer in cardiology. Am J Cardiol 1963;11:697702 